\section{The evolution of eyes: major steps. The Keeler lecture 2017: centenary of Keeler Ltd}

\begin{abstract}
Ocular evolution is an immense topic, and I do not expect to cover all the details of this process in this manuscript. I will present some concepts about some of the major steps in the evolutionary process to stimulate your thinking about this interesting and complex topic. In the prebiotic soup, vision was not inevitable. Eyes were not preordained. Nor were their shapes, sizes, or current physiology. Sight is an evolutionary gift but it was not ineluctable. The existence of eyes is so basic to our profession that we often do not consider how and why vision appeared or evolved on earth at all. Although vision is a principal sensory modality for at least three major phyla and is present in three or four more phyla, there are other sensory mechanisms that could have been and were occasionally selected instead. Some animals rely on other sensory mechanisms such as audition, echolocation, or olfaction that are much more effective in their particular niche than would be vision. We may not believe those sensory mechanisms to be as robust as vision, but the creatures using those skills would argue otherwise. Why does vision exist at all? And why is it so dominant at least in the number of species that rely upon it for their principal sensory mechanism? How did vision begin? What were the important steps in the evolution of eyes? How did eyes differentiate along their various paths, and why? Eye (2018) 32, 302-313; doi:10.1038/eye.2017.226; published online 20 October 2017
\end{abstract}

The ocular toolkit

Selection of visually responsive compounds

Received: 27 July 2017

Accepted: 31 July 2017

Published online:

20 October 2017
Retinal Life probably first appeared $\sim 3.7$ billion years ago as a simple cell with the ability to replicate. Current extant cyanobacteria
IR Schwab

represent an early form, or more likely they are a direct descendent, of such ancient cells. The oldest fossils of cyanobacteria can be found in the form of stromatolites (Figure 1). The sun's light, limited only by its physical properties, was, and is, the principal source of energy for such cells. The very short wavelengths such as $\mathrm{X}$-rays and gamma rays create free radicals and would be damaging to cells. The longer wavelengths such as radio waves do not carry enough energy and are too large to permit much discrimination. The visible and nearly visible light from the near ultraviolet extending into the infrared, though, would be useful if this energy could be captured without harm to the cell. These frequencies would be the sweet spot providing sufficient energy yet small enough to permit good discrimination. To use the sun's light would require conversion of these critical wavelengths to energy to fuel cellular metabolism.

A cyanobacterium was likely the first organism and probably became the first chloroplast by endosymbiosis. ${ }^{1,2}$ This singlecelled organism with its new chloroplast was the first cell to use this rather narrow band of the sun's emissions to produce energy. This process would eventually green the planet, and permitted the production of beta caroteneessential to the production of retinal for the rhodopsin that would follow.

Opsins The opsin in rhodopsin probably evolved from a G-protein coupled receptor (GPCR) protein although this origin is murky. ${ }^{3}$ $\mathrm{G}$ proteins are rather common and rather easily produced, but the first 'opsins' were not true GPCR. Rather these early opsin-like compounds combined with retinal that functioned as a proton pump for energy production for certain Archaea. ${ }^{4,5}$ The passage of such molecules from microbial opsins to metazoan opsins probably came from a common ancestor as these are related, albeit distantly. ${ }^{5}$ 


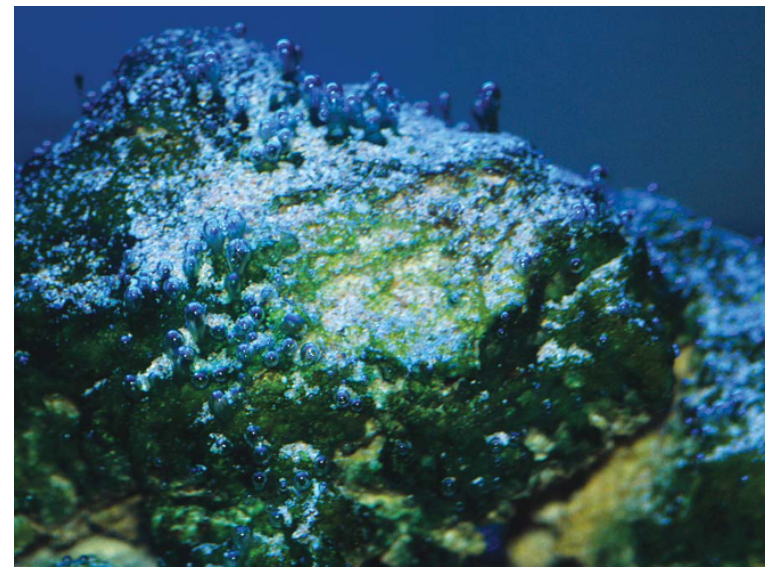

Figure 1 Stromatolites are alive today and this small formation from Shark Bay in Western Australia illustrates the oxygen that is given off by the cyanobacteria that compose the stromatolite.

Retinal and its eventual congeners and an opsin served as the basis for the principal family of metazoan photoreceptive compounds-the ciliary opsins, rhabdomeric opsins, and the photoisomerases. ${ }^{6}$ These were not the only photoreceptive compounds available to first life as other compounds such as the flavins, porphyrins, biliproteins, and chlorophyll among others could have been sufficient for the transduction of light to the energy to power a biochemical signal. However, under certain circumstances these compounds could be toxic or photosensitizing to cells. These other compounds were not able to compete as successfully with rhodopsin for the principal photoreceptive one although the flavins are retained in many Metazoa as light-sensing molecules in the form of cryptochromes. ${ }^{7,8}$ This biochemistry was crucial to our use of rhodopsin and cryptochromes.

Genetic anlage Certainly, rhodopsin is essential to the eventual evolution of eyes, but that is only a start. The Pax gene family joined the party although in a primitive form and gradually evolved. The predecessor of these ancient genes can be found in organisms as basal as some sponges $^{9,10}$ and some cnidarians (the jellies) as PaxB. Jellies (better named as jellies as these are not fish) are not considered in our lineage meaning that the last common ancestor of jellies and most other metazoan creatures must have had a similar protein that was eventually bequeathed to all triploblasts ${ }^{11,12}$ because we did not descend from the jellies.

With the combination of retinal as a chromophore, and an opsin with a GPCR structure, and with the genetic anlage to make an eye, the toolkit had begun.

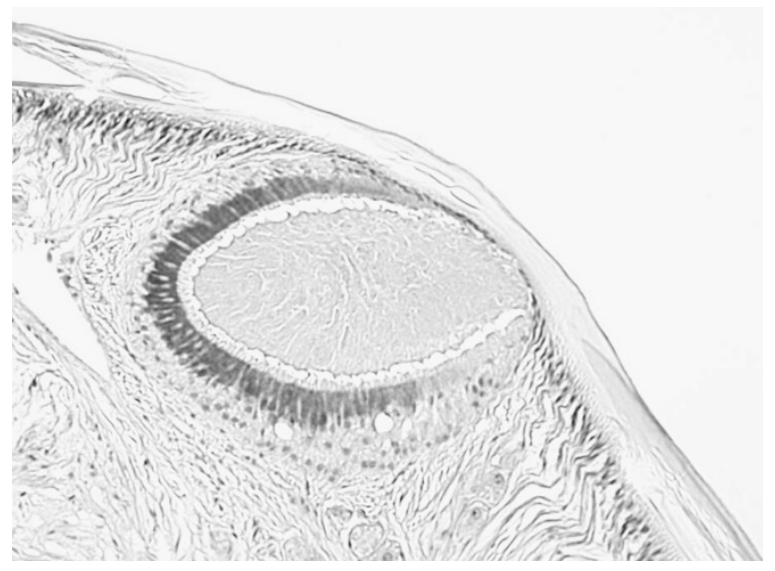

Figure 2 Nereis virens-King sandworm: note the eyecup but no lens. This provides some spatial information for the animal although its vision is poor. Nevertheless, it is a predator. Histologic section by Richard Dubielzig DVM.

\section{Formation of an eye}

\section{From an eyespot to a simple eye}

Once an opsin (or the predecessor of the opsins) covalently bonded with retinal, perhaps in a cell with a cilium or two, the slow crawl to an eye began. Instead of studding the cellular membrane with bacteriorhodopsin as might be seen in Halobacterium solarium, these compounds came together in an eyespot, and evolution co-opted the molecule for sight instead of using it as a proton pump.

Multiple light-sensing cells in an eyespot in a multicellular animal, such as a leech could recognize only light or dark. Perhaps after 35000 generations, an organism discovered that developing a concave cup instead of a spot produced a more successful and competitive organ for sight. ${ }^{12}$

As Nilsson and Pelger ${ }^{12}$ suggested, from an eyespot to an eyecup to a fully formed camera-style eye could take as few as 364000 generations, and the production of such an eye in perhaps as short a period as half a million years. Of course, there would be more to an eye than just a cup, but that is a key step (Figure 2), and that cup may fit the real definition of an 'eye.' If one assumes that the eye must provide spatial information to be defined as an eye, then the curvature of a cup would create the first eye, as primitive spatial information would be provided. Such an eye can be seen in the limpet. ${ }^{13}$ Progress toward a more typical eye could proceed quickly in geological terms with the sides of the cup creating a pinhole as can be seen in the abalone $\mathrm{e}^{13}$ or the nautilus eye $\mathrm{e}^{14}$ (Figure 3 ). Crystalline lenses were added later on in the eye's evolutionary history. This explains why different lineages have surprisingly different compounds composing their lenses. Trilobites have calcite, invertebrates have recruited a 


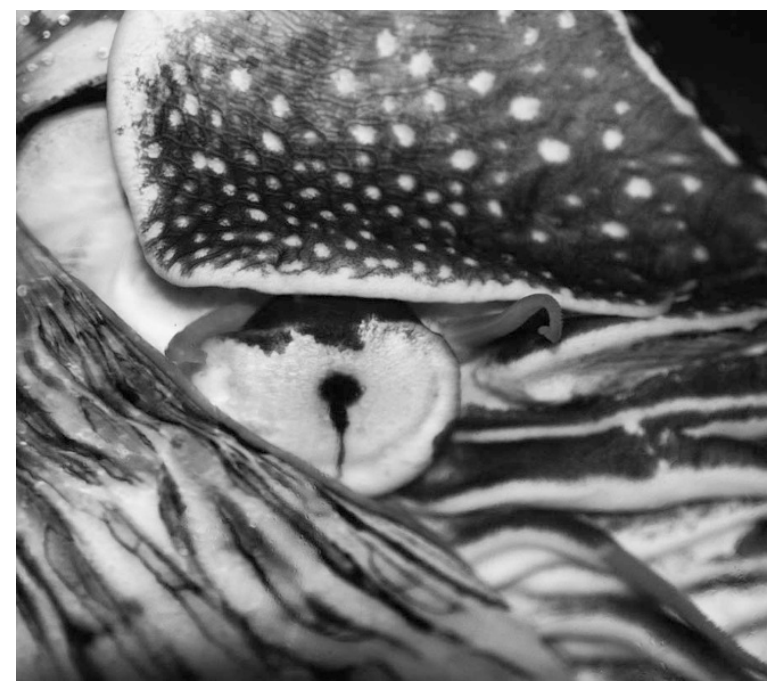

Figure 3 Nautilus: note the nautilus eye with a pinhole but no cornea. The eye is embedded with the body with the histology seen in Figure 8.

variety of crystallins and some novel proteins, ${ }^{15}$ and vertebrates have a wide variety of somewhat similar crystallins, mostly heat-shock proteins. ${ }^{16,17}$ Evolution has selected whatever enzyme or heat-shock protein was available, often co-opted from other functions, to design and fashion metazoan lenses. This indicates that lenses are relative latecomers in the development of the eye, and are often taxon-specific. As these compounds are biochemically different, they differ in their ability to be deformed. Fish lenses, for example, are quite hard and deform very little, but most avian lenses are soft and quite ductile.

\section{From an eyespot to a camera-style eye}

A camera-style eye is a simple eye, but we think of a camera-style eye as more complex than just a cup with a pinhole. A cornea, lens, extraocular muscles (EOMs), and ocular adnexa were added as necessary for the occupied niche. Hence, there are differences in these structures suggesting independent and often, convergent evolution. For example, some spiders and humans both have six EOMs, but these are completely unrelated in embryology and function. ${ }^{18}$

\section{From an eyespot to a compound eye}

Light-sensing cells in an eyespot have at least one additional method of forming an eye. Instead of forming a cup, those cells could form a bulge or convex protrusion of the cellular layer, again providing spatial information and hence an eye. This pattern later added a lens and then often a second lens proximal to the first lens to create the

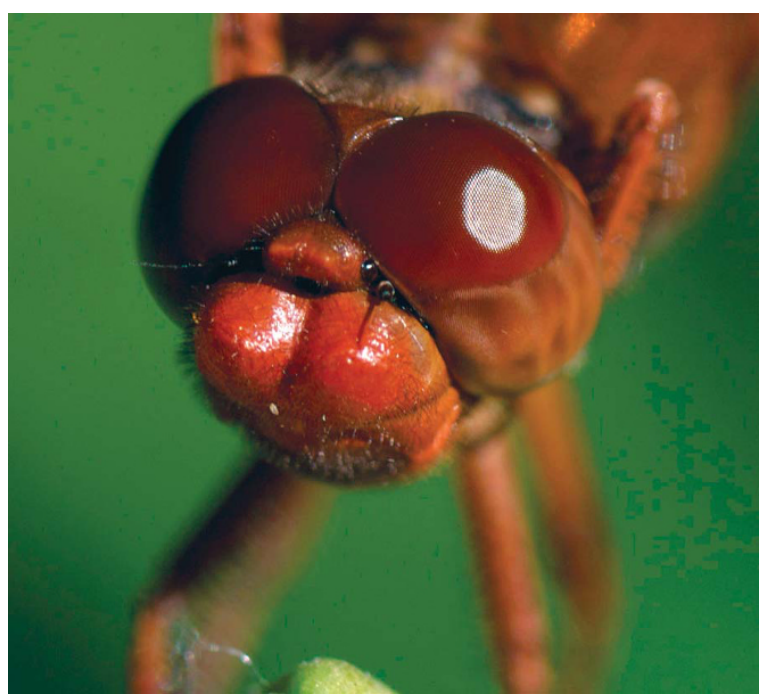

Figure 4 Dragonfly sp. Note the multiple ommatidia. Many species have $\sim 30000$ individual hexagonal units with a horizontal band of smaller and more concentrated ommatidia for a finer image.

individual unit of a compound eye, called an ommatidium (pl. ommatidia Gr. 'little eyes.') Multiple such ommatidia would likely have been produced by gene duplication eventually leading to as many as 30000 individual units as found in a dragonfly (Figure 4).

The morphology of the compound eye would itself evolve and radiate into at least six general categories (some of the general categories have subcategories) of compound eyes, including these: (1) apposition; (2) afocal apposition; (3) neural superposition; (4) refracting superposition; (5) parabolic superposition; and (6) reflecting superposition. ${ }^{19}$

Each of these models provides different optics and neurologic channels necessary to fit the niche represented. The details of optics and physiology of these eyes are extensive and can be found elsewhere. ${ }^{19,20}$

Once the basic pattern of ocular development had become established, the vast spans of time permitted the tinkering necessary to fashion all manner of eyes on earth.

\section{Proterozoic era 2200-543 million years ago}

\section{Further preparation for metazoa}

The cyanobacteria and other anerobes that had been cooking away for $\sim 1500$ million years produced oxygen as a waste product. These same organisms were intolerant of this gas, which led to the appearance of eukaryotes at $\sim 1.7-2.0$ billion years ago. ${ }^{21}$ Eukaryotes appeared and evolved with the help of mitochondria as endosymbionts. These were the earliest protists, and preceded the early and ancient multicellular animals such as the Porifera 


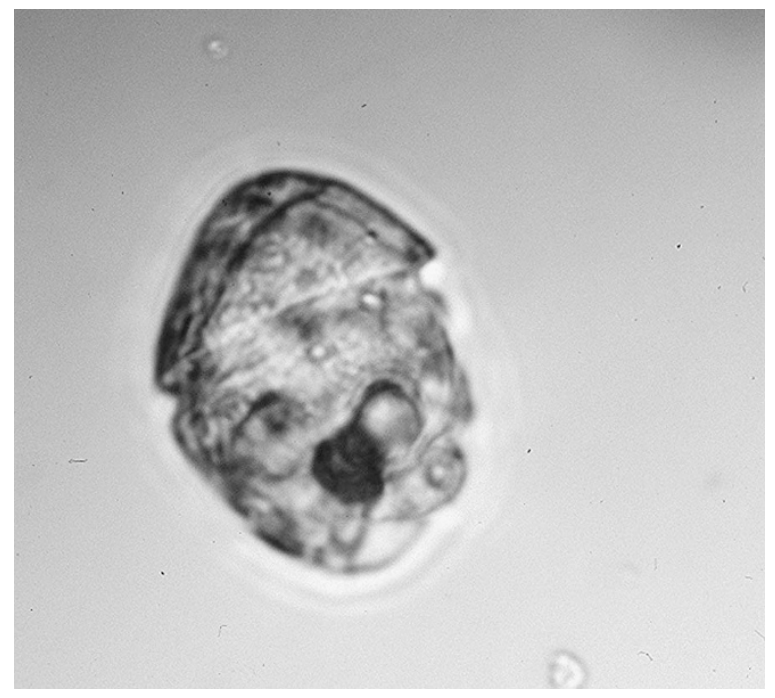

Figure 5 Nematodinium: this dinoflagellate, a protist, is $\sim 70 \mu \mathrm{m}$ in length and has an ocelloid seen in the lower half. There is a pigment cup with a retina-like structure and a lens-like structure. It is a predator but has no brain. Image FJR 'Max' Taylor PhD.

(sponges). Sponges do not have eyes, but are lightsensitive using cryptochromes mentioned above and appeared $\sim 650-700$ million years ago (mya), ${ }^{22}$ although controversy surrounds this dating. These creatures never developed eyes but do rely on the sun's energy for metabolism and reproduction. The protists, though, would illustrate just how far evolution can go in a single cell.

\section{Creativity in evolution}

The protists are still with us today, and have been present on earth for the aforementioned 1.7-2.0 billion years. ${ }^{23}$ These creatures have continued to evolve and develop just as other lineages have. Some have even developed a camera-style eye.

Dinoflagellates are protists, and include a few with an ocelloid that looks eerily like an eye (Figure 5).

Erythropsidium (a dinoflagellate) is $\sim 50-70 \mu \mathrm{m}$ in length and contains a camera-style eye composed of subcellular elements. ${ }^{23}$ Although little is known about its genetics or visual mechanisms, we do know that this remarkable eukaryote betokens evolution's creativity and the importance of vision. How this organism interprets the image it receives remains a mystery and it is doubtful that this organism interprets any image to much extent. It has no brain whatsoever. The camera-style eye, though is undeniable although it is better described as an ocelloid. ${ }^{23}$

The ocelloid is compromised of pre-existing organelles or bits of organelles that are mostly mitochondria and anastomosing plastids. These organelles are believed to have originated through ancient symbiosis with a red $\operatorname{alga}^{23}$ or perhaps other protists. Endosymbiosis is a way of life for these creatures as they also have a chloroplast presumably subsuming a cyanobacterium.

These components, then, are acquired from other dinoflagellates or other single-celled organisms and assembled into a complex structure that is light-sensitive and probably permits some form of spatial vision as these creatures are predators hunting other protists. ${ }^{23-25}$ This suggests that these protists could be autotrophic (photosynthetic) when light is plentiful and switch to being heterotrophic (consume other organisms) if light is scarce.

The dinoflagellates are not the only organisms to possess a remarkable eye to be found in what would otherwise be considered simple creatures. Cnidaria (jellies, corals, and a few parasites) illustrate another step in convergent evolution with the development of an eye in what might be considered to be a basal phylum and not in the lineage of vertebrates or invertebrates.

\section{Another evolutionary accomplishment}

The cnidarians (jellies) would arise in the Ediacaran (635543 mya) at about the same time or shortly after the sponges. Eventually, this lineage would lead to jellies including the box jellies. At least two of these in the Class Cuboza have camera-style eyes. One of these (Tripedia cystophora) has been studied in some detail providing insight into its visual mechanisms. This box jelly has four sides (this explains the name 'box jelly') and near the lower edge of the bell on each side are pendent structures called rhopalia. Each rhopalium ends in a club-like structure containing six eyes (Figure 6). Two of these eyes are camera-style eyes and the other four are simple pitlike structures. Although this creature has only a single visual pigment in its retina, it does have a cornea, crystalline lens, and a retina (Figure 7) ${ }^{26}$ Nevertheless, this is a diploblast (two germ layers) with a camera- style eye suggesting that an eye is relatively easy for evolution to produce and that a true brain may not be necessary to its function.

\section{Cambrian explosion (543-505 mya)}

Although a fantastic array of animals of many different phyla appeared during the Cambrian explosion, it likely that most of these biologic experiments did not succeed. Yet, even now there are $~ 36$ phyla. Only 7 of these phyla have eyes and only 4 have image-forming eyes. Three of those 4, mollusca, arthropoda, and chordata, account for $96 \%$ of species. These 3 phyla were all present in the Cambrian explosion, though each may have arisen much earlier in the Ediacaran, 650-543 mya. Chordates may have been the latest of the 3 to arise. 


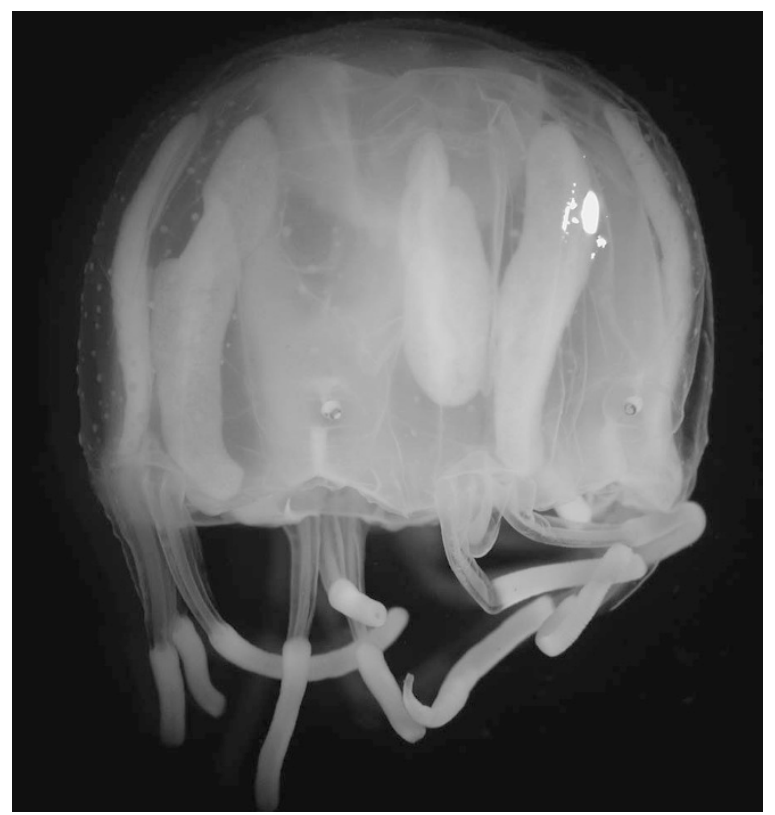

Figure 6 Tripedalia cystophora (a box jelly): this thumb-jointsized jelly has four 'sides' and a cord-like structure on each side called a rhopalia. Each rhopalia has six eyes with two of those being camera style. Although the quality of discrimination cannot be good, this creature is a predator and uses visual cues to catch its prey.

\section{First known eyes}

The fossil record reveals the first known eye was in a trilobite, Olenellus fowleri. Although doubtful it is the first eye, it is the first known eye because of the calcite composition of its ommatidia (the individual units of a compound eyes.) Calcite, a crystal of limestone, is already a form of stone so does not need to fossilize to be preserved. This ancient arthropod probably lived between 600 and 550 mya before the Cambrian explosion and possessed fully formed eyes with multiple individual ommatidia. ${ }^{27-29}$ Classically, though, we currently accept that the oldest Olenellus comes from the middle or early Cambrian.

This would suggest that eyes were forming well before the Cambrian period but no record of such pre-Cambrian trilobites, or other animals with eyes, exists, at least to date.

\section{Compound eyes begin}

As discussed earlier, the compound eye began, possibly in a worm-like creature, preceding the trilobites or contemporary to them. These creatures or others in their lineage eventually radiated into annelids, mollusks, and arthropods. All three of these lineages possess members that have compound eyes, but the arthropods have perfected this ocular model. There are at least six different

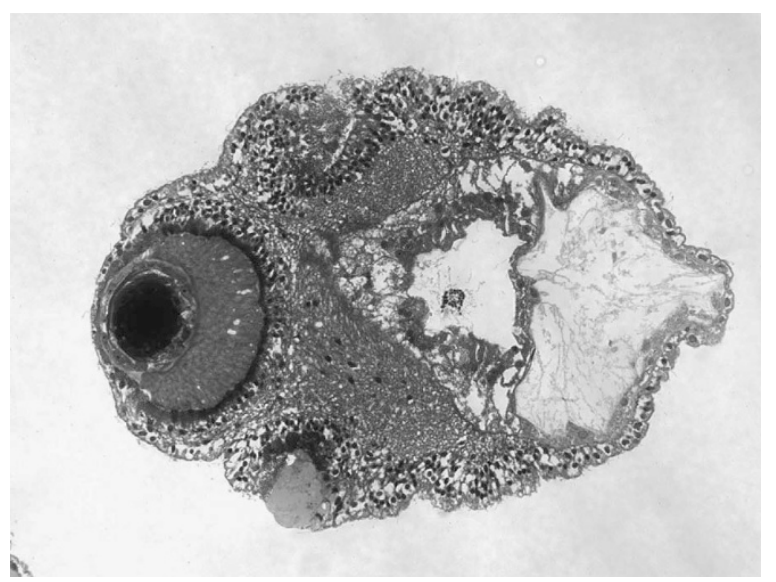

Figure 7 Tripedalia cystophora (a box jelly): the terminal bulb of one of the rhopalia of this jelly showing a camera-style eye and the outline of a pit eye along the lower edge.

models of compound eyes and it would appear that the most likely explanation is that the apposition-style eye came first and radiated into the other forms although this explanation is not completely satisfactory. ${ }^{19,20}$

For example, the apposition eye and afocal apposition (seen in butterflies) are surprisingly similar. Even the eye of a more distantly related sabellid worm is anatomically similar suggesting that these compound eyes are closely related too.

Throughout the world of compound eyes, the similarities in anatomy, physiology, and optics suggests that these six basic models are homologous and developed from one another or from a common ancestor. $^{20}$

\section{Mollusks}

The mollusks exploded during the Cambrian as well, and they may possess the greatest diversity of eyes seen in any phylum. Arthropods might disagree, but mollusks have great variety including as many as 10 different ocular models with some unique varieties. Perhaps the most unusual eye among mollusks is found in the scallop.

Scallops possess an unusual eye that represents one of a kind. The eye has two layers of retina behind the crystalline lens using mirror optics to focus the image on the more distal retinal layer. One retina has ciliary receptors and the other has rhabomeric receptors, and the eye would appear to be quite sophisticated. But, these eyes that circle the mantle of the scallop are little more than shadow detectors to alert the scallop to predators as there is no real brain to interpret the image. ${ }^{30-32}$

There are other unusual ocular models found among the mollusks. For instance, cephalopods include the nautilus, which has a pinhole camera for an eye with no lens and no cornea ${ }^{33}$ (Figure 8 ). The nautilus is an ancient 


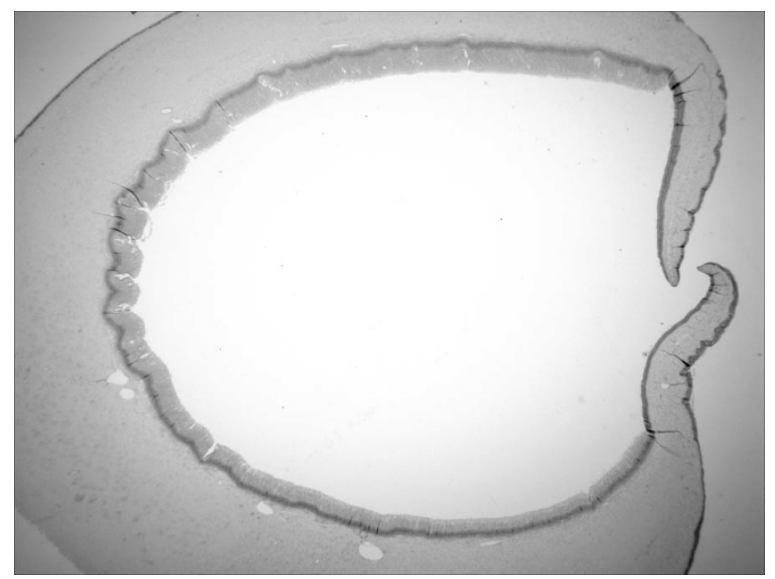

Figure 8 Histology of the eye of the nautilus: note the pinhole for focusing and the absence of the lens. Although the interpretation of the image would require much light, this mechanism would provide an image with surprising spatial information.

member of the class Cephalopoda that arose 500+ mya. The octopus evolved later and exhibits a more derived eye that includes a lens, a horizontally oval pupil, and a highly sophisticated system of EOMs. Depending on the squid or octopus, there maybe from 7 to 14 EOMs that provide excellent control to the orientation of the pupil and hence the image ${ }^{34}$ among other derived characteristics.

\section{Vertebrates}

The Cambrian was a beginning for vertebrates too. Perhaps, it was Pikaia or Haikouella, the conodonts, or some other related creature, that could be considered as the first chordate leading to the first vertebrate in the Cambrian. We do know that vertebrates arose in or before the Cambrian and probably resembled the agnathans-or jawless fish.

The agnathans are the closest extant relative to the first cephalochordates alive today, so we must rely upon them to help us understand the development of eyes in the early vertebrate lineage.

The vertebrate eye appears in these early animals as a camera-style eye and begins the process of maturation. The eye begins as a cyst, fully independent of the external integument (Figure 9). ${ }^{35}$ Although controversy swirls around the question of whether the hagfish or lamprey is the oldest extant vertebrate, we can be certain that the lamprey is indeed an ancient vertebrate and will serve as the best extant approximation of the early vertebrates.

The southern lamprey, Geotria australis, has been well studied and shows a surprisingly mature camera-style eye. The animal has five visual pigments with three or four of that are found in more evolved fish. ${ }^{35}$ During the

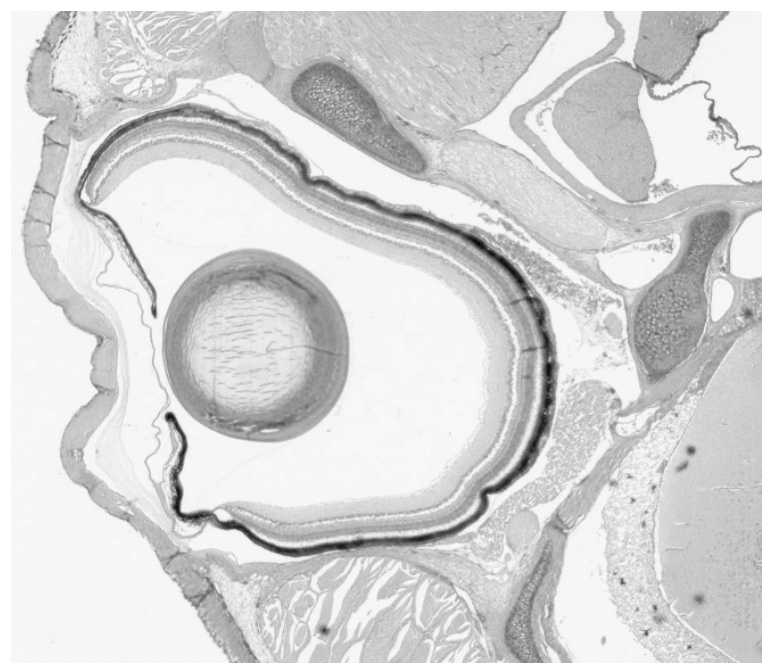

Figure 9 Histology of the lamprey eye (Petromyzon marinus). Although this is a basal vertebrate, the eye appears very much like a vertebrate eye. Note, however, the very thin cornea, which is separated from the overlying integument. Histologic section by Richard Dubielzig DVM.

adult phase of life, the southern lamprey has a retina that closely resembles that of fish and even mammals. The camera-style eye had begun and although there would be important modifications, the anatomy and physiology would remain similar to this original eye. As it is so sophisticated, we know that its beginnings had to be much earlier in the early chordates and the maturation within the true vertebrate was just a continuation of the process.

The lamprey eye resembles the general model for the fish eye although the fish eye has evolved and developed in many ways such as a more intricate vascular supply and retinal complexity. ${ }^{36,37}$ The general anatomy of the fish eye helps explain the challenges faced by aquatic animals, and how the eye evolved to meet those challenges.

\section{The Devonian 415-362 mya}

\section{Development of the fish eye}

Fish proliferated during the Devonian, which has been called the age of fishes. The general model of this camerastyle eye, which began with the agnathans would be relatively large globes to body size, a fixed pupil in most members of the lineage, a flat cornea as the index of refraction of water is nearly equal to that of the cornea depriving the cornea of its refractive abilities, a nearly perfectly round large lens, and accommodation by lens movement rather than lens deformation (Figure 10). Of course, there are exceptions to this general model and a great variety of designs occur. ${ }^{38}$ 


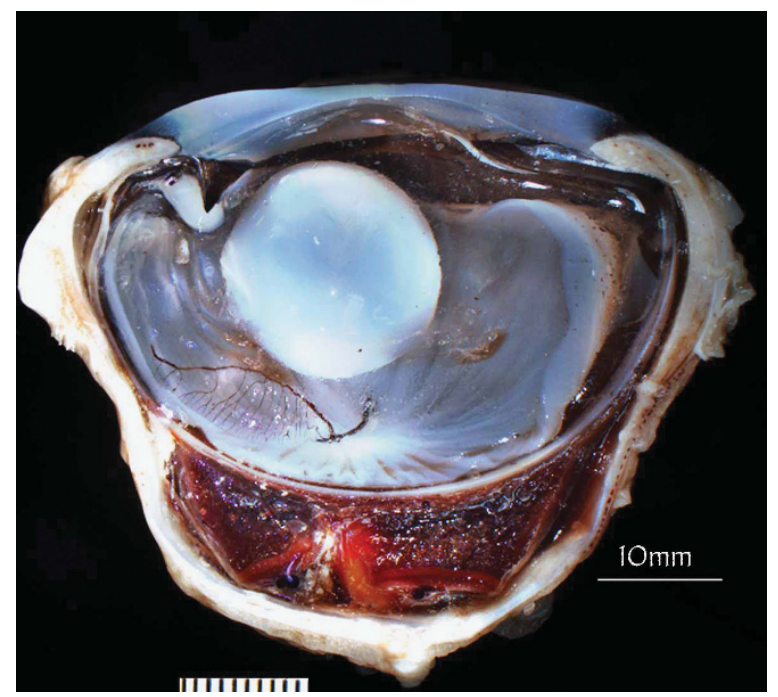

Figure 10 Histology of the eye of a Bluefin tuna (Thunnus thynnus). Note that the equatorial diameter is $\sim 60 \mathrm{~mm}$ and the anterior-posterior diameter measures $\sim 40 \mathrm{~mm}$ although the eye has lost some size and volume during processing. This is a flat eye with a large round lens. Note also the 'choroidal gland' behind the macula, which is actually a plexus of blood vessels for nutrition and to provide warmth for the contents of the eye. Histologic section by Richard Dubielzig DVM.

\section{Invertebrate predators come ashore}

The Devonian was an important period for terrestrial creatures as well. The mosses and liverworts gradually became tolerant of dry land, or at least swamp land and came ashore. Vegetation attracted insect grazers, which in turn attracted predators such as early peripatetic arachnids, including spiders.

Some spiders developed excellent eyesight and clever adaptations to squeeze the optics and neurologic equipment into very small spaces. Take, for example, the rather winsome jumping spider.

Although the jumping spider was not present in the Devonian, it evolved from the stock that did come ashore during that period. Some extant jumping spiders evolved a set of remarkable eyes as its central, principal eyes with a large single lens affixed to the carapace (giving them a large eye 'look' and a charming demeanor) and connected to a comparatively long tube. At the end of the tube are vertically stacked photoreceptors (for comparison, human photoreceptors are horizontally arrayed) containing three, or in some cases four, visual pigments (Figures 11 and 12). The external lenses are fixed and do not move externally, but the internal tubes scan horizontally. These data are combined, probably much like a raster scan on a television, in a tiny brain to create the image. The other three sets of eyes are mainly for the enlargement of the visual field. ${ }^{39,40}$

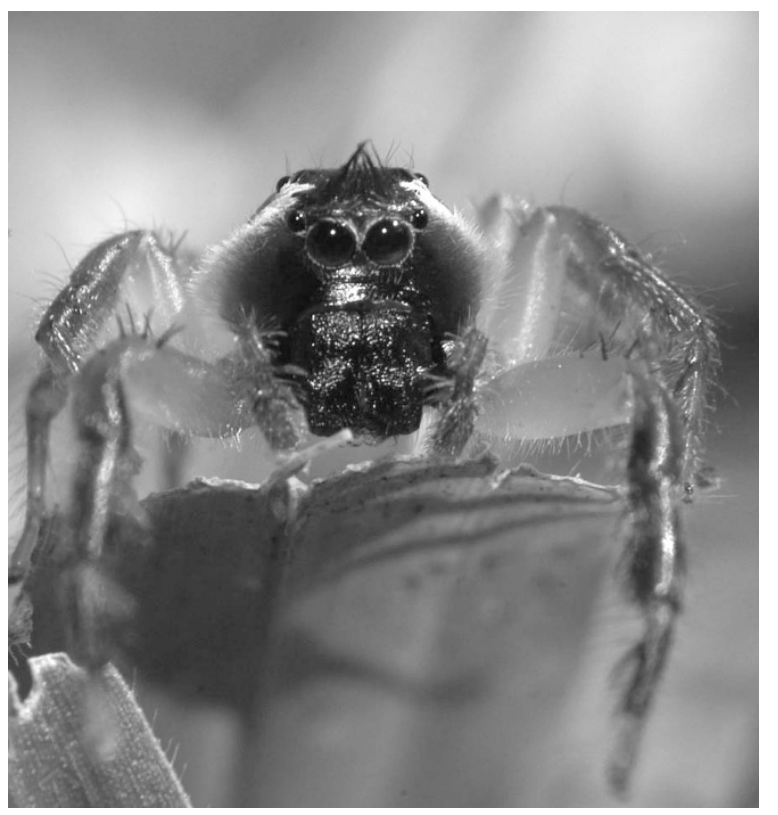

Figure 11 Mopsus mormon (green jumping spider): note large anterior median eyes giving an appearance of a curious child. Some jumping spiders have tetrachromatic vision. The anterior lateral eyes can be seen on the creature, and these eyes have good vision as well.

The tetrapods followed the early invertebrate predators by coming ashore in the late Devonian. This was a major step in the evolution of the vertebrate eye as several major changes to the fish eye model were required.

\section{Gaining ground among the vertebrates}

Shubin and his team discovered the fossil of Tiktaalik, which probably represents the transitional form from an aquatic animal to a terrestrial one. ${ }^{41-43}$

This major step required adaptations to terrestrial life that can be considered in extant amphibians. Although the current lineage of frogs is not part of the amphibious lineage that would lead to mammals, this group can help us understand the necessary changes.

Appearing about 374-360 mya, extant amphibians such as frogs show important steps to adapt to an aerial interface for the eye. The cornea became steeper and clearer, a nictitans (third eyelid) and external eyelids appeared. The earliest creature with a nasolacrimal duct is thought to have been Eusthenopteron or Osteolepis both of which were considered ancient lobe-finned fish. ${ }^{44}$ The lobe-finned fish include extant lungfish and the relict coelacanth.

Extant frogs also show important neurologic steps toward binocularity. Critically, stereopsis depends on visual inputs from each eye going to both sides of the 


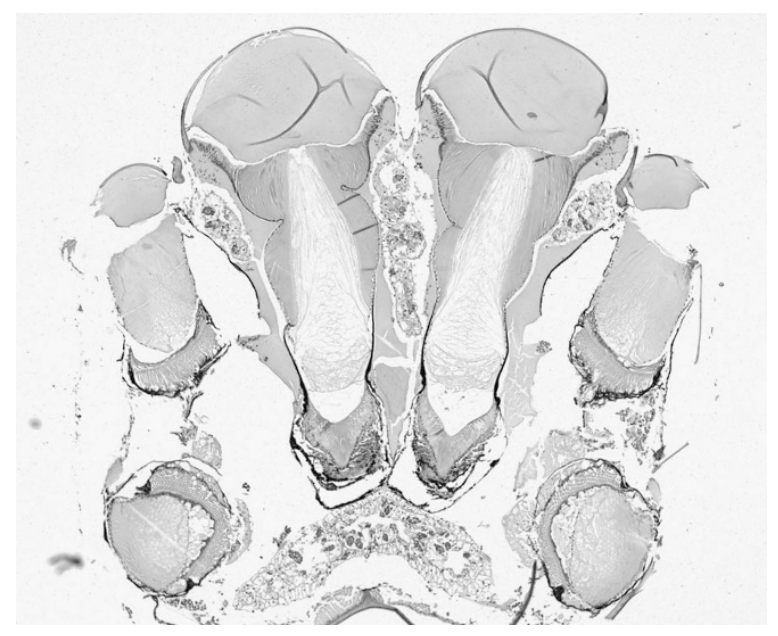

Figure 12 Histology of jumping spider eye. Note the single lens in the 'tube-like' eye. The second refractive element in this eye is the convexiclivate fovea. The pit in the 'retina' causes light rays to diverge when striking the interface between the gel within the tube and 'retina.' Histologic section by Richard Dubielzig DVM.

brain. Most fish have a completely crossed chiasm, but most mammals have a partially decussated chiasm to achieve stereopsis. Where would this change occur? The answer is to be found in the early amphibious tetrapods, if frogs are to be our model. As tadpoles, frogs have a completely crossed chiasm, just like fish. ${ }^{45-47}$ During metamorphosis, the retinal growth cones head toward the chiasm are divided there and directed to go to one or the one or the other optic tract in about equal numbers. Phylogenetically, this represented the first partially decussated chiasm. ${ }^{45-47}$

The assumption of a terrestrial lifestyle required many adaptations not only for the eye but also in the management of reproduction. Extant amphibians cannot move far from water, because they are required to lay their eggs in water. The cleidoic egg changed that. A cleidoic egg (or amniotic egg) is one with a leathery or hard shell that limits evaporation and does not require constant contact with water. For some animals such as placental mammals, the amniotic egg is internal and thus does not need the outer and impervious shell. This permitted newly terrestrial animals to move away from water sources.

\section{The Carboniferous 362-299 mya}

\section{Radiation of true terrestrial vertebrates}

Cotylosaurs, with their sprawling four legs and awkward gait were perhaps the ancestors of all terrestrial animals after arising from the early amphibious tetrapods. They were the stem reptiles and radiated into two distinct lineages-Sauropsids and Synapsids.

\section{Sauropsids}

Sauropsids diverged into two distinct lineages: Lepidosaurs, including lizards, the tuatara, and eventually snakes and Archosaurs, including turtles, crocodiles, and eventually birds.

This was a major step for the terrestrial eye because the crystalline lens slimmed to the shape of a lentil and accommodation was accomplished by lens deformation instead of lens movement. This key step using striated musculature in most sauropsids and was faster, more accurate and produced a brighter image than lens movement. All lineages of sauropsids and synapsids are believed to have developed accommodation by lens deformation. Snakes are an exception. Snakes radiated from the lizard lineage and lost this ability during their fossorial sojourn, only to revert to lens movement for accommodation when they emerged from underground. By then, though, they had lost the ability for accommodation of any kind. Hence, evolution found a different manner of accommodation using lens movement analogous to that of fish. This rather clumsy method of accommodation by lens movement consists of squeezing the vitreous to push the lens forward and backward is analogous to, but not homologous to accommodation in fish. ${ }^{48}$

One interesting and insightful extant Lepidosaur is the Tuatara. This creature reveals what the status of the sauropsids was at about the time of the divergence of the lepidosaurs and the archosaurs. The tuatara has a welldeveloped parietal eye complex including a 'cornea' in the form of a clear portion in the middle of a scale on the dorsal surface of the head. The parietal eye resembles other camera-style eyes, until one looks more closely. Beneath the 'cornea' is a somewhat disorganized eye, a vitreous cavity and a pigment epithelium that sits atop the ciliated photoreceptive cells of what resembles a retina. In other words, the pigment epithelium is distal to the photoreceptors interposed between the lens and the retina! This enigmatic organ is not phylogenetically new, however, as it is also found in some lampreys and various fish. ${ }^{49}$ The retina contains single and double cones, which have the electron microscopic characteristics of cones. This suggests that as a crepuscular or nocturnal animal, the tuatara has cone-like photoreceptors that have acquired rod-like characteristics and functions. ${ }^{50}$

The archosaurs evolved along a similar but somewhat divergent path and that lineage eventually led to the dinosaurs. Although our knowledge of dinosaurian vision is limited, we can make some assumptions based on the last common ancestor, indirectly related creatures and extant progeny including direct descendants. We can conclude that at least some dinosaurs had tetrachromatic 
vision, accommodation by lens deformation, and likely a parietal eye.

We can conclude much of this from the avian lineage as birds are living dinosaurs having radiated from the theropod dinosaur lineage. Although current evidence is controversial, Archaeopteryx is believed to be the first known bird capable of flight, but newer finds from China suggest that there were earlier creatures that might qualify as the first bird such as flightless Sapeornis. These ancient birds may argue over primacy, but the radiation of these creatures has been magnificent-especially on a visual basis.

Avian adaptations offer some affirmation of the eyes of preceding theropods from which birds arose, and provide us a glimpse into what is almost certainly the best visual system on earth.

Many birds have astonishing adaptations that are conceptually difficult for us since we cannot extend our senses to fully grasp what they mean. For example, many birds have four visual pigments and see into the ultraviolet range. Some birds have a flicker fusion rate that is triple our own, yet have a movement sense of as little as $15^{\circ}$ an hour..$^{51-53}$ Such a movement rate allows as bird with such a skill to see the sun or moon move across the horizon. Some birds, and maybe all, have a double chiasm so that those birds obtain stereopsis with a neurologic mechanism analogous to that of humans. ${ }^{54}$ Many of the predatory birds including raptors have two foveae one of which is used for best distant acuity and the other is used in concert with the second fovea in the other eye for stereopsis at closer range. ${ }^{55}$ The avian lineage is definitely eye-minded and most birds have eyes that are larger than their brains, often with retinae that are three times thicker than those of humans, suggesting that much more of the visual processing is happening in their retina. Birds with the best vision have foveal concentrations of photoreceptors at $\sim 1000000 / \mathrm{mm}^{2}$ compared to our own concentration of $\sim 200000 / \mathrm{mm}^{2}$. 56,57

\section{Synapsids}

The stem reptiles, the cotylosaurs, diverged into two different lineages, the sauropsids (discussed above) and the synapsids. These creatures arose about 286-221 mya from a common amniote and would eventually evolve from reptile to mammal. Mammals arose 200-210 mya.

Monotremes (egg-laying mammals) arose about 166 mya before the mammalian lineage and their eyes more closely resemble reptilian eyes than those of marsupials and placental mammals. Monotremes have clear oil droplets, scleral cartilage, and double cones found in reptiles and birds but not in placental mammals. There are other subtle differences in the eye that cleave toward the reptilian eye than toward the placental mammal eye. ${ }^{58}$
Marsupials arose $~ 148$ mya, arising after the monotremes and with a more derived eye. Marsupials lack the scleral cartilage, but most have double cones and oil droplets seen in many of the reptilian lineages and birds, but not in placental mammals. There are a few other differences between the marsupials and the more derived placental mammals. ${ }^{59,60}$

The more derived mammals, the placental mammals, would explode and radiate in variety after the comet strike at Chicxulub. Placental mammals would continue to evolve over the next 65 million years, and provide an important illustration of how evolution works, namely, color vision.

\section{Neurobiology of color vision}

First, a bit of a primer on color vision. In the vertebrate lineages, there are four major visual pigment families and these are important to understand especially as we follow color vision along the evolutionary trail. The visual pigment families include the following:

1. Short wavelength 1 (SWL1) with its wavelength peak at about $415 \mathrm{~nm}$.

2. Short wavelength 2 (SWL2) with its wavelength peak at $455 \mathrm{~nm}$.

3. Middle wavelength (MWL) with its peak wavelength at $508 \mathrm{~nm}$.

4. Long wavelength (LWL) with its peak wavelength at $571 \mathrm{~nm} .61-63$

It is not known for certain whether the early synapsids had color vision, but they almost certainly did, and likely tetrachromacy. As we will see in the radiations of this lineage, there is evidence to suggest that these same four visual pigments carried well toward the animal that would carry the distinct definition of a mammal but it is not certain when and where the losses began.

\section{Monotremes}

As discussed above, the first radiation of mammals was probably the monotremes, and they were likely more numerous initially than they are now. There are but three (some authorities believe there to be five) species extanttwo species of echidna and one species of platypus. Two of these representative species are found only in Australia, and the other is found New Guinea. The monotremes became nocturnal, and lost two visual pigments SWL1 and MWL, leaving only SWL2 and the LWL. Hence they have dichromatic color vision. The genetic machinery is present for the SWL1 although it is not expressed and is incomplete suggesting that it was 
lost though mutation and was not advantageous enough to keep on an evolutionary basis. ${ }^{61,63}$

\section{Marsupials}

The story of color vision in the marsupials is, as of yet, not fully told. It would seem certain that (most) of the marsupials retain the SWL2 and LWL visual pigment and are at least dichromatic, but there is a report that two of the marsupials, the fat-tailed dunnart and the honey possum have a MWL as well. ${ }^{64}$ This is disputed although there are two additional marsupials with the genetic tools to have the MWL but it is not clear if this is expressed. ${ }^{65}$ This distribution of visual pigments in the marsupials can provide us with several conclusions.

First, at least three of the four visual pigments found in fish can also be found in various mammals, SW1, SW2, and the LWL. This indicates that as the mammalian radiation occurred, the four visual pigments may have been fully functional up until the beginning of the mammals and perhaps even into this lineage. And, we can say that the visual pigments were not lost at once but rather over millions of years, even if we cannot explain why these were lost. The questionable conclusion is whether all four visual pigments came as far as the marsupials, and that part of the story is not yet complete. ${ }^{2}$

The last common ancestor of the marsupials and the placental mammals eventually radiated into the placental mammals at $\sim 125$ mya, ${ }^{66}$ and by this time all that remained of the visual pigments in the lineage was the SWL2 and the LWL. Most placental mammals retain this configuration and the dichromatic color vision that accompanied those two visual pigments.

The color vision story does not end there yet, of course, because it does not yet include the primates and within that lineage, humans. ${ }^{67}$

\section{Primates}

Primates diverged from the last common ancestor about 77 mya into what would perhaps best be called a protoprimate. This creature was probably dichromatic and present on a gigantic continent called Gondwanaland, which included what is now Africa, South America, Antarctica, India, and Madagascar. Gondwanaland broke up into its component pieces about 100-120 mya, taking the protoprimate with it, likely to all pieces of this ancient continent. Eventually, these basal primates radiated into three distinct groups, the Prosimii or prosimians (lemurs, bush babies, lorises, pottos, and the tarsiers), the Platyrrhina (New World monkeys), and the Catarrhina (Old World monkeys). ${ }^{61,66}$

The prosimians are closest to the basal primates and they remain dichromatic but are still part of the story.
The Old World monkeys were separated from the New World monkeys and evolved a third visual pigment that has a peak wavelength that is shorter than the LWL already present in that group. This third visual pigment is not the same one as found in fish, reptiles, or birds, and likely represents an error in duplication of the LWL visual pigment. This 'error' probably occurred $\sim 40$ mya. For whatever reason, this visual pigment was a significant advantage to the lineage and it spread throughout this group. ${ }^{61,66}$

The visual photopigments in New World monkeys are not as consistent, and as a result, they illustrate visual photopigment evolution in progress. The Howler monkeys species (Alouatta seniculus and Alouatta caraya) are the only exceptions, although there maybe a second species following a similar path. Each animal has three predictable visual photopigments similar to those of the Old World monkeys and each is a trichromat. As in Old World monkeys, gene duplication at a relatively unstable locus formed the third visual pigment. That means that when New World and Old World monkeys separated, all were dichromats. As the opsins in the Howlers are similar to those in the Old World monkeys, this suggests that the genetic material (called polymorphisms) was present in both Old World and New World monkeys when they separated, but these genetic tools were not active in either group. ${ }^{61,66}$

At least three other species of New World monkeys are dichromats now but are developing a third active visual photopigment in some of their cones, suggesting that evolution is progressing toward trichromacy in these animals, too.

The females of two diurnal lemurs (closely related to the Black and White Ruffed Lemur) have recently been found to have polymorphisms that would permit some individuals to have the visual photopigments required for trichromacy. This suggests that lemurs are ready to develop three visual photopigments and hence trichromacy, but this has not happened. This helps confirm that the different lineages of primates were dichromats when they diverged. Furthermore, the lack of trichromacy among lemurs suggests that competition has not yet demanded it.

Trichromacy requires more than the necessary visual photopigments in the cones and cone concentration; the neurologic mechanisms to interpret and compare these signals must be in place as well. This adds further evidence to the principle that the eye (and other sensory mechanisms) drives the brain and not the reverse. Either the two must evolve in tandem, or the sensory mechanism evolves first and co-opts other neurologic machinery. ${ }^{66}$ There is subtle evidence that some of the New World monkeys have given up some olfaction to gain trichromacy and this suggests that these neurologic 
channels of the elements of the lost olfaction sense has been co-opted for the third visual pigment although this has not been proven. Similarly, some microbats have lost SWS1 expression while gaining the use of echolocation hinting that the neural channeling was co-opted for this purpose..$^{63,66}$

\section{Conclusions}

The evolution of eyes has taken several major steps in development. Some of the eye steps have been discussed above. We know from computer models, ${ }^{12}$ and deductive reasoning, that eyes can evolve quickly. Eyes may have evolved as many as 40 times during metazoan development. Some basic eye molecules, such as retinal and the opsins, are highly conserved and present throughout most multicellular animals. Other proteins such as those that comprise the crystalline lenses, when they are present, are not as highly conserved because they were cobbled together later in species development after divergence from other species. Similarly there is a dazzling array of ocular designs for different niches and different visual environments.

\section{Conflict of interest}

The author declares no conflict of interest.

\section{References}

1 Reith M, Munholland J. Complete nucleotide sequence of the Porphyra purpurea chloroplast genome. Plant Mol Biol Rep 1995; 13: 333-335.

2 McFadden GI. Chloroplast origin and integration. Plant Physiol 2001; 125: 50-53.

3 Feuda R, Hamilton SC, McInerney JO, Pisani D. Metazoan opsin evolution reveals a simple route to animal vision. Proc Natl Acad Sci USA 2012; 109: 18868-18872.

4 Grote M, Engelhard M, Hegemann P. Of ion pumps, sensors and channels-perspectives on microbial rhodopsins between science and history. Biochim Biophys Acta 2014; 1837: 533-545.

5 Porter ML. Beyond the eye: molecular evolution of extraocular photoreception. Integr Comp Biol 2016; 56: 842-852.

6 Shichida Y, Matsuyama T. Evolution of opsins and phototransduction. Philos Trans R Soc Lond B Biol Sci 2009; 364: 2881-2895.

7 van der Spek PJ, Kobayashi K, Bootsma D, Takao M, Eker $\mathrm{AP}$, Yasui A. Cloning, tissue expression, and mapping of a human photolyase homolog with similarity to plant bluelight receptors. Genomics 1996; 37: 177-182.

8 Griffin EA, Staknis D, Weitz CJ. Light-independent role of CRY 1 and CRY2 in the mammalian circadian clock. Science 1999; 286: 768-771.

9 Suga H, Tschopp P, Graziussi DF, Stierwald M, Schmid V, Gehring WJ. Flexibly deployed Pax genes in eye development at the early evolution of animals demonstrated by studies on a hydrozoan jellyfish. Proc Natl Acad Sci USA 2010; 107: 14263-14268.
10 Kozmik Z, Daube M, Frei E, Norman B, Kos L, Dishaw LJ et al. Role of Pax genes in eye evolution: a cnidarian PaxB gene uniting Pax2 and Pax6 functions. Dev Cell 2003; 5: 773-785.

11 Vopalensky P, Kozmik Z. Eye evolution: common use and independent recruitment of genetic components. Philos Trans R Soc Lond B Biol Sci 2009; 364: 2819-2832.

12 Nilsson DE, Pelger S. A pessimistic estimate of the time required for an eye to evolve. Proc Biol Sci 1994; 256: 53-58.

13 Land MF, Nilsson DE. Animal Eyes. Oxford University Press: New York, NY, USA, 2002, pp 56-57.

14 Schwab IR. Evolution's Witness: How Eyes Evolved. Oxford University Press: New York, NY, USA, 2012, pp 73-75.

15 Tomarev SI, Piatigorsky J. Lens crystallins of invertebrates: diversity and recruitment from detoxification enzymes and novel proteins. Eur J Biochem 1996; 235: 449-465.

16 Duncan MK, Cvekl A, Kantorow M, Piatigorsky J. Lens crystallins. In: Robinson ML, Lovicu FJ (eds). Development of the Ocular Lens. Cambridge University Press: Cambridge, UK, 2004, pp 119-150.

17 Piatigorsky J, Wistow G. The recruitment of crystallins: new functions precede gene duplication. Science 1991; 252: 1078-1079.

18 Schwab IR. Evolution's Witness: How Eyes Evolved. Oxford University Press: New York, NY, USA, 2012, pp 114-117.

19 Schwab IR. Evolution's Witness: How Eyes Evolved. Oxford University Press: New York, NY, USA, 2012, pp 50-62.

20 Land MF, Nilsson DE. Animal Eyes. Oxford University Press: New York, NY, USA, 2002, pp 125-177.

21 Davidov Y, Jurkevitch E. Predation between prokaryotes and the origin of eukaryotes. BioEssays 2009; 31: 748-757.

22 Gold DA, Grabenstatter J, de Mendoza A, Riesgo A, Ruiz-Trillo I, Summons RE. Sterol and genomic analyses validate the sponge biomarker hypothesis. Proc Natl Acad Sci USA 2016; 113: 2684-2689.

23 Gavelis GS, Hayakawa S, White RA, Bojobori T, Suttle CA, Keeling $\mathrm{P}$ et al. Eye-like ocelloids are built from different endosymbiotically acquired components. Nature 2015; 523: 204-207.

24 Dodge JD. The functional and phylogenetic significance of dinoflagellate eyespots. Biosystems 1984; 16: 259-267.

25 Kreimer G. Reflective properties of different eyespot types in dinoflagellates. Protist 1999; 150: 311-323.

26 Garm A, Coates MM, Gad R, Seymour J, Nilsson DE. The eyes of the box jellyfish Tripedalia cystophora and Chiropsalmus sp. are slow and color-blind. J Comp Physiol A Neuroethol Sens Neural Behav Physiol 2007; 193: 547-557.

27 Fortey RA, Briggs DEG, Will MA. The Cambrian evolutionary 'explosion': decoupling cladogenesis from morphological disparity. Biol J Linnean Soc 1996; 57: 13-33.

28 Lieberman BS. Phylogenetic analysis of some basal early Cambrian trilobites, the biogeographic origins of the eutrilobita, and the timing of the Cambrian radiation. J Paleontol 2002; 76: 692-708.

29 Lieberman BS. Taking the pulse of the Cambrian radiation. Integr Comp Biol 2003; 43: 229-237.

30 Speiser DI, Johnsen S. Comparative morphology of the concave mirror eyes of scallops (Pectinoidea). Am Malacol Bull 2008; 26: 27-33.

31 Schwab IR. Evolution's Witness: How Eyes Evolved. Oxford University Press: New York, NY, USA, 2012, pp 70-72.

32 Land MF, Nilsson DE. Animal Eyes. Oxford University Press: New York, NY, USA, 2002, pp 130-135. 
33 Messenger JB. Photoreception and vision in molluscs. In: Cronly-Dillon JRE, Gregory RL (eds). Vision and Visual Dysfunction, 2nd Vol. Macmillan: Basingstoke, UK, 1991, pp 64-397.

34 Budelmann BU, Yound JZ. The oculomotor system of decapod cephalopods: eye muscles, eye muscle nerves, and the oculomotor neurons in the central nervous system. Philos Trans R Soc Lond B Biol Sci 1993; 340: 93-125.

35 Collin SP, Potter IC, Braekevelt CR. The ocular morphology of the southern hemisphere lamprey Geotria australis gray with special reference to optical specializations and the characterization and phylogeny of photoreceptor types. Brain Behav Evol 1999; 54: 96-118.

36 Yu C, Schwab IR, Dubielzig RR. Feeding the vertebrate retina from the Cambrian to the Tertiary. J Zool 2009; 278: $1-11$.

37 Schwab IR. Evolution's Witness: How Eyes Evolved. Oxford University Press: New York, NY, USA, 2012, pp 249-252.

38 Schwab IR. Evolution's Witness: How Eyes Evolved. Oxford University Press: New York, NY, USA, 2012, pp 85-108.

39 Land MF. Movements of the retinae of jumping spiders (Salticidae: Dendryphantinae) in response to visual stimuli. J Exp Biol 1969; 51: 471-493.

40 Schwab IR. Evolution's Witness: How Eyes Evolved. Oxford University Press: New York, NY, USA, 2012, pp 115-117.

41 Daeschler EB, Shubin NH, Jenkins FA Jr. A Devonian tetrapod-like fish and the evolution of the tetrapod body plan. Nature 2006; 440: 757-763.

42 Shubin N. Your Inner Fish: A Journey into the 3.5-Billion-Year History of the Human Body. University of Chicago Press: New York, NY, USA, 2008.

43 Clack JA. Getting a leg up on land. Sci Am 2005; 293: 100-107.

44 Rich PV, Rich TH, Fenton MA, Fenton CL. The Fossil Book: A Record of Prehistoric Life. Dover Pub: Mineola, NY, USA, 1997, p 370 .

45 Hoskins SG. Control of the development of the ipsilateral retinothalamic projection in Xenopus laevis by thyroxine; results and speculation. J Neurobiol 1986; 17: 203-229.

46 Nakagawa S, Brennan C, Johnson KG, Shewan D, Harris WA, Holt CE. Ephrin-B regulates the ipsilateral routing of retinal axons at the optic chiasm. Neuron 2000; 25: 599-610.

47 Hoskins SG, Grobstein P. Induction of the ipsilateral retinothalamic projection in Xenopus laevis by thyroxine. Nature 1984; 307: 730-733.

48 Walls G. The Vertebrate Eye. The Cranbrook Institute of Science: Bloomfield Hills, MI, USA, 1942, pp 260-263.

49 Ung CY, Molteno AC. An enigmatic eye: the histology of the tuatara pineal complex. Clin Exp Ophthalmol 2004; 32: 614-618.

50 Meyer-Rochow VB, Wohlfahrt S, Ahnelt PK. Photoreceptor cell types in the retina of the tuatara (Sphenodon punctatus) have cone characteristics. Micron 2005; 36: 423-428.
51 Jones MP, Pierce KE Jr, Ward D. Avian vision: a review of form and function with special consideration to birds of prey. J Exotic Pet Med 2007; 16: 69-87.

52 Boström JE, Dimitrova $\mathrm{M}$, Canton $\mathrm{C}$, Håstad $\mathrm{O}$, Qvarnström A, Ödeen A. Ultra-rapid vision in birds. PLoS ONE 2016; 11: e0151099.

53 Healy K, McNally L, Ruxton GD, Cooper N, Jackson AL. Metabolic rate and body size are linked with perception of temporal information. Anim Behav 2013; 86: 685-696.

54 Ehrlich D, Zappia JV, Saleh CN. Development of the supraoptic decussation in the chick (Gallus gallus). Anat Embryol 1988; 177: 361-370.

55 Ruggeri M, Major JC Jr, McKeowan C, Knighton RW, Puliafito CA, Shuliang J. Retinal structure of birds of prey revealed by ultra-high resolution spectral-domain optical coherence tomography. Invest Ophthalmo Vis Sci 2010; 51: 5789-5795.

56 Snyder AW, Miller WH. Telephoto lens system of falconiform eyes. Nature 1978; 275: 127-129.

57 Collin SP. Behavioural ecology and retinal cell topography. In: Archer SN, Djamgoz MBS, Loew ER, Partridge JC, Vellarga S (eds). Adaptive Mechanisms in the Ecology of Vision. Kluwer: Dordrecht, Netherlands, 1999, pp 509-535.

58 Zeiss CJ, Schwab IR, Murphy CJ, Dubielzig RW. Comparative retinal morphology of the platypus. J Morphol 2011; 272: 949-957.

59 Stanley RG. Marsupial ophthalmology. Vet Clin North Am Exot Anim Pract 2002; 5: 371-390.

60 McMenamin PG, Krause WJ. Morphological observations on the unique paired capillaries of the opossum retina. Cell Tissue Res 1993; 271: 461-468.

61 Jacobs GH. The evolution of vertebrate color vision. In: Lopez-Larrea C (ed.). Sensing in Nature. Springer: New York, NY, USA, 2012, pp 156-172.

62 Hunt DM, Peichl L. S cones: evolution, retinal distribution, development, and spectral sensitivity. Vis Neurosci 2014; 31: $115-138$.

63 Jacobs GH, Rowe MP. Evolution of vertebrate colour vision. Clin Exp Optom 2004; 87: 206-216.

64 Jacobs GH. Losses of functional opsin genes, short-wave length cone photopigments, and color vision-a significant step in the evolution of mammalian vision. Vis Neurosci 2013; 30: 39-53.

65 Arrese CA, Hart N, Beazley LD, Shand J. Trichromacy in marsupials. Curr Biol 2002; 12: 657-660.

66 Arrese CA, Oddy AY, Runham PB, Hart NS, Shand J, Hunt $\mathrm{DM}$ et al. Cone topography and spectral sensitivity in two potentially trichromatic marsupials, the quokka (Setonix brachyurus) and quenda (Isoodon obesulus). Proc Biol Sci 2005; 272: 791-796.

67 Zhao H, Rossiter SJ, Teeling EC, Li C, Cotton JA, Zhang S. The evolution of color vision in nocturnal mammals. Proc Natl Acad Sci USA 106: 8980-8985. 